\title{
Processed coffee alleviates DSS-induced colitis in mice
}

\author{
1,2 Bernd L. Fiebich*, ${ }^{3}$ Amaya G. Vinuesa, ${ }^{3}$ Gonzalo Sanchez-Duffhues, ${ }^{3}$ Juan A. \\ Collado, ${ }^{1}$ Thorsten Rose, ${ }^{4}$ Jörn Menthe, and ${ }^{3}$ Eduardo Muñoz
}

\begin{abstract}
${ }^{1}$ VivaCell Biotechnology GmbH, Ferdinand-Porsche-Str. 5, D-79211 Denzlingen, Germany; ${ }^{2}$ Department of Psychiatry and Psychotherapy, University of Freiburg Medical School, Hauptstr, 5, D-79014 Freiburg, Germany; ${ }^{3}$ Departamento de Biología Celular, Fisiología e Inmunología, Facultad de Medicina. Universidad de Córdoba, Avda Menendez Pidal s/n. 14004 Córdoba, Spain; ${ }^{4}$ J.J. Darboven GmbH \& Co KG, Pinkertweg 13, D- 22113 Hamburg, Germany
\end{abstract}

*Corresponding author: Bernd Fiebich, PhD, VivaCell Biotechnology GmbH, FerdinandPorsche-Str .5, D_79211 Denzlingen, Germany, Department of Psychiatry and Psychotherapy, University of Freiburg Medical School, Hauptstr. 5, D-79014 Freiburg, Germany

Submission date: April 12, 2013; Acceptance date: May 29, 2013; Publication date: May 30, 2013

\section{ABSTRACT:}

Background: Coffee is one of the most widely consumed beverages in the world and it has been demonstrated that it has important therapeutic activities not only because of its caffeine content but also owing to the presence of other biologically active small molecules such as chlorogenic acid, trigonelline and cyclopentadiones. However, chlorogenic acid is degraded into catechol, pyrogallol and hydroxyhydroquinone, which are thought to induce irritation of the gastric mucosa. To reduce the content of irritant compounds processing methods have been developed prior to roasting the coffee beans.

Objectives: The aim of this study was to study the anti-inflammatory and gastro-protective effects of processed coffee (Idee-Kaffee) on in LPS-treated human primary monocytes and in a murine model of colon inflammation (IBD model).

Results: In this study we have analyzed the effects on inflammatory events in cultured cells and in mice drinking a commercially available processed coffee. The processed coffee inhibited lipopolysaccharide (LPS)-induced proinflammatory cytokines such as interleukin (IL)-1 $\beta$, tumor necrosis factor (TNF) $\alpha$, IL-6 and IL-8, and other inflammatory mediators such as prostaglandin $(\mathrm{PG}) \mathrm{E}_{2}$ and 8-isoprostane in cultured human primary monocytes. Oral administration of dissolved processed coffee, i.e., in its usual beverage form, improved greatly the adverse macroscopic and histological features of dextran sodium sulfate (DSS)induced colitis in mice in a dose-dependent manner. Processed coffee not only largely

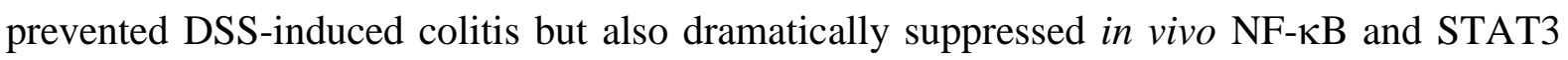
activities through inhibition of IкB $\alpha$ and STAT3 phosphorylation. Furthermore, this soluble 
coffee bean extract reduced the expression of proinflammatory cytokines TNF $\alpha$, IL-11, and IL-6 and the expression of cyclooxygenase (COX)-2 in colonic tissues.

Conclusions: This work identified processed coffee as an anti-inflammatory beverage with the capacity to reduce substantially DSS-induced colitis as well as the colitis-associated cellular inflammatory events.

Keywords: coffee, Inflammatory Bowel Disease, NF-кB, STAT3, cytokines

\section{BACKGROUND:}

Diet and lifestyle are known to play a major role in the development of many diseases associated with subclinical chronic inflammation. Thus, dietary compounds are of special relevance for improving the body's defenses against such diseases. There is increasing evidence that coffee, one of the most widely consumed beverages in the world, is associated with a reduced risk to develop chronic diseases for which inflammation is a major driving force [1]. For instance, coffee consumption has been associated with a reduced risk of neuroinflammatory diseases [2], chronic liver diseases [3.4], cardiovascular diseases [5], and type 2 diabetes mellitus [6]. Moreover, a meta-analysis study revealed a potential protective role of coffee in colon carcinogenesis [7], which has been associated with inflammation [8]. However, the precise mechanisms of action of coffee and/or coffee compounds have not been elucidated yet.

Many of the biological activities of coffee are mediated by caffeine, but the antioxidant activity of coffee is mainly ascribable to phenolic compounds such as chlorogenic acid, diterpenoid compounds such as kahweol, cafestol and reaction products known as Maillard products formed during the roasting process [9]. Some degradation products of chlorogenic acid such as pyrocatechol, hydroxy-hydroquinone and pyrogallol are potential gastric irritant substances present in coffee drinks. To reduce stomach mucosal irritation green coffee beans are treated with steam under certain conditions of temperature, pressure, vacuum and humidity over a period of 2-3 h to reduce the content of chlorogenic acid and to manufacture a "stomach-friendly" coffee [10]. Such processed coffee induced significantly less mucosal irritation in healthy volunteers $[11,12]$.

In addition to anti-irritant effects in gastric mucosa, processed coffees apparently retain some of the beneficial activities attributed to non-processed coffee. For instance, coffee extracts inhibit LPS-induced nuclear factor kappa-B (NF- $\mathrm{B})$ activation and induce the cellular antioxidant defense through the activation of the Nrf2 pathway. Interestingly, the degree of roasting was critical for the level of the anti-NF- $\kappa \mathrm{B}$ and antioxidant activities [13]. Furthermore, the activation of phase II detoxifying enzymes in the liver of mice fed with coffee has been reported [14]. Interestingly, neither chlorogenic acid nor other phenolic compounds present in the coffee were found to inhibit LPS-induced NF- $\kappa$ B activation or induce Nrf2-dependent transcription. Moreover, filtered ground-up coffee, which lacks most of the initial diterpene content, is also a potent inhibitor of LPS-induced NF- $\kappa B$ activation [13].

Chronic inflammatory bowel diseases (IBD), mainly ulcerative colitis and Crohn's disease are naturally remitting and recurring conditions of the digestive tract. The 
pathophysiology of IBD is related to an exacerbated immune response in which macrophage hyperactivation plays a key role. Moreover, chronic inflammatory conditions such as those occurring in the gastrointestinal tract of IBD patients are known to increase the risk of colorectal cancer [14]. Indeed, inflammation is associated with $15-20 \%$ of all cancer deaths $[15,16]$. The STAT3 (Signal transducer and activator of transcription 3) and NF- $\kappa$ B signaling pathways play crucial roles in colonic inflammation and in inflammation-induced cancer [1719].

The aim of the present study was to test the intestinal anti-inflammatory effects of dietary administration of a commercially available processed coffee (Idee Coffee) in the DSS model of colitis, an experimental model of intestinal inflammation that has some of the histological and biochemical features of the human disease [20]. As mentioned above, in previous studies this coffee has been described as stomach friendly 11,12], and we therefore were interested if this processed coffee also reveals anti-inflammatory effects. Special attention was paid to the effects exerted by coffee on the production of some of the macrophage-derived mediators involved in the inflammatory response.

\section{METHODS:}

Coffee. Commercially available coffee samples (typically ground to a fine powder after roasting) were prepared from beans, which had been treated by a special roasting and processing method before grinding [10]. The coffee extracts (arabica variety) tested in this study were prepared by the following method: The extracts, i.e., their special fine coffee powder, was delivered by Darboven in vacuum containers and stored at $4^{\circ} \mathrm{C}$. Twenty grams of each dry coffee sample was dissolved in $250 \mathrm{ml}$ of water and boiled for $10 \mathrm{~min}$ ("brewed"), and the coffee solution was allowed to stand and settle. When it had cooled to room temperature it was filtered through Whatman filter paper (GE Healthcare Europe, Barcelona, Spain). Fresh coffee was prepared every morning.

Animals. C57BL/6J wild-type mice were purchased from Charles River (Barcelona, Spain) and bred in our facilities. Before treatment 8-10 week old mice were housed under standard conditions and supplied with drinking water and food ad libitum. Water was substituted with diluted $(50 \% / 50 \%$ coffee/water $\mathrm{vol} / \mathrm{vol})$ or undiluted coffee at least 2 weeks before DSStreatment and we found that the animals did not reject the drink. During this acclimation period no changes in behavior were detected. All experiments were performed according to the Institutional Guidelines for the Care and Use of Laboratory Animals in Research and with the approval of the local ethics committee of the University of Cordoba.

Colitis induction. The animals ( $\mathrm{n}=6$ each group) were treated with $2.5 \%$ dextran sodium sulfate (DSS, m.w. 36-50 kDa) (MP Biomedicals, Irvine, CA, USA) either in the drinking water or in the coffee beverage over five days, followed by 4 days of regular water or coffee. A sweetener was added to the beverage consumption during the DSS treatment and the amount of liquid drunk was monitored daily. Daily clinical assessment of DSS-induced colitis was performed, including measurement of food intake and body weight, evaluation of stool consistence, and testing for the presence of blood in the stools by a guaiac paper test. Stool consistence was assessed using the following 4-point scale: 0, normal; 1, loosely shaped pellets; 2, amorphous, moist pellets; 3, diarrhea; 4, presence of blood. The rate of 
survival was $100 \%$. The mice were sacrificed at day 7 by $\mathrm{CO}_{2}$ and colon removed, measured and divided longitudinally to use half sample for protein or RNA extraction ( $n=3$ samples per group) and the other half for inclusion in paraffin as indicated.

Histological analysis. Intestines were removed and processed by standard procedures. In brief, colons were fixed as "Swiss rolls" overnight in $10 \%$ neutral buffered formalin. Then colons were washed with PBS and transferred into $70 \%$ ethanol, processed and embedded into paraffin. Sections of the size of $5 \mu \mathrm{m}$ were cut for hematoxylin and eosin staining.

RNA analysis and RT-PCR determination. Total RNA was extracted from frozen colons using an RNAeasy Mini Kit (Qiagen, Hilden, Germany). Disruption and homogenization of the tissue was performed using a rotor-stator homogenizer (T10 basic Ultra-Turrax, IKA, Staufen, Germany). DNase-treated RNA $(1 \mu \mathrm{g})$ was used for the synthesis of cDNA with SuperScript II Reverse Transcriptase (Invitrogen, San Diego, CA, USA) according to the manufacturer's instructions. Reverse Transcriptase-PCR (RT-PCR) amplification was performed in a $50 \mu \mathrm{l}$ PCR reaction mixture containing 1 to $5 \mu \mathrm{l}$ of the retro-transcription mixture, 1x PCR buffer, $1.5 \mathrm{mM} \mathrm{MgCl}_{2}, 200 \mu \mathrm{M}$ dNTPs, $10 \mu \mathrm{M}$ each of 5' and 3' primers, and 2.5 units of recombinant TaqDNA polymerase. The mixtures were amplified in a MultiGene cycler IR system (Labnet, Labnet, Woodbridge, NJ, USA). The amplification protocol consisted of an initial denaturation for $3 \mathrm{~min}$ at $95^{\circ} \mathrm{C}$ and then 40 cycles of $30 \mathrm{~s}$ at $95^{\circ} \mathrm{C}$, annealing for $30 \mathrm{~s}$ at $55^{\circ} \mathrm{C}\left(\mathrm{COX}-2\right.$; TNF $\alpha$ and IL-6) or $50^{\circ} \mathrm{C}$ (IL-11), and elongation for $30 \mathrm{~s}$ at $72{ }^{\circ} \mathrm{C}$. A cycle of $10 \mathrm{~s}$ at $83{ }^{\circ} \mathrm{C}$ and a final extension for $30 \mathrm{~s}$ was carried out at 72 ${ }^{\circ} \mathrm{C}$. The primers used to detect inducible proinflammatory genes were:

COX-2: Forward: 5' TGAGCAACTATTCCAAACCAGC 3’; Reverse: 5' GCACGTAGTCTTC GATCACTATC 3'

TNF $\alpha$ : Forward: 5'-ACGGCATGGATCTCAAAGAC-3'; Reverse: 5' GTGGGTGAGGAGCAC GTAGT 3'

IL-6: Forward: 5’ GTATGAACAACGATGATGCACTTG 3’; Reverse:

5’ATGGTACTCCAGA AGACCAGAGGA 3

IL-11: Forward: 5' CTGCACAGATGAGAGACAAATTCC 3’; Reverse: 5' GAAGCTGCAAA GATCCCAATG 3'

GAPDH: Forward: 5’ TGGCAAAGTGGAGATTGTTGCC 3’; Reverse: 5' AAGATGGTGAT GGGCTTCCCG 3’

Western blot analysis. The intestines were opened up and snap-frozen at $-80^{\circ} \mathrm{C}$ and were kept there until processed for protein extraction. Comparable amounts of tissue from distal or medial colon were homogenized with Ultra-Turrax in lysis buffer $(50 \mathrm{mM}$ Tris- $\mathrm{HCl} \mathrm{pH} 7.5$, $150 \mathrm{mM} \mathrm{NaCl}, 10 \%$ glycerol, $10 \% \mathrm{NP} 40)$ and supplemented with phosphatase inhibitors (500 mM NaF, $200 \mathrm{mM} \mathrm{Na}_{3} \mathrm{VO}_{4}$ ) and protease inhibitors (Leupeptin, Aprotinin, Pepstatin, saturated PMSF). Western blotting was performed and immunodetection of specific proteins

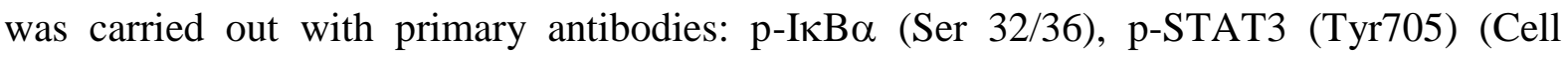
Signaling, Danvers, MA, USA), and $\alpha$-Tubulin (Sigma-Aldrich, ST Louis, MO, USA), using an ECL system (GE Healthcare Europe, Barcelona, Spain).

Isolation of human peripheral monocytes. Monocytes from healthy human donors were 
prepared following a standardized protocol (Ficoll gradient preparation, GE Healthcare Europe GmbH, Freiburg, Germany) using a completely endotoxin-free cultivation). Using 50 $\mathrm{ml}$ tubes, $25 \mathrm{ml}$ Ficoll was loaded with $25 \mathrm{ml}$ blood of buffy coats from healthy blood donors. The gradient was established by centrifugation at $1800 \mathrm{rpm}$, at $20{ }^{\circ} \mathrm{C}$ for $40 \mathrm{~min}$ using slow acceleration and braking. Peripheral blood mononuclear cells in the interphase were carefully removed and re-suspended in $50 \mathrm{ml}$ pre-warmed phosphate buffered saline followed by centrifugation for $10 \mathrm{~min}$ at $1600 \mathrm{rpm}$ and $20{ }^{\circ} \mathrm{C}$. The supernatant was discarded and the pellet washed in $50 \mathrm{ml}$ PBS and centrifuged as described above. The pellet was then resuspended in $50 \mathrm{ml}$ RPMI-1640 low endotoxin-medium (from Invitrogen) supplemented with $10 \%$ human serum (PAA). After counting the number of cells in a particle counter (Euro Diagnostics, Krefeld), cells $\left(10^{6} / \mathrm{ml}\right)$ were seeded in 24 -well plates $(2 \mathrm{ml})$ and incubated at $37^{\circ} \mathrm{C} / 5 \% \mathrm{CO}_{2}$. The medium and the non-adherent cells (lymphocytes) were removed and fresh RPMI-1640 medium containing 1\% human serum was added. Monocytes were then ready to be used for the experiments.

Determination of inflammatory parameters. Measurements of the cytokines IL-6, TNF $\alpha$, IL-8 and IL-1 $\beta$, PGE $_{2}$ and 8-isoprostane were performed using commercially available EIAs ( $\mathrm{PGE}_{2}$ : Biotrend, Köln, Germany, 8-isoprostane: Cayman, distributed by Alexxa, Lörrach, Germany) and ELISA (IL-6, TNF $\alpha$; IL-8 and IL-1 $\beta$ : HISS, Freiburg, Germany) kits. Cells were seeded in 24-well plates (Falcon) for EIA-/ELISA measurements. Then, 30 min prior to stimulation with LPS $(10 \mathrm{ng} / \mathrm{ml})$ cells were incubated with the coffee solutions at the indicated concentrations. After incubation at $37^{\circ} \mathrm{C}$ and $5 \% \mathrm{CO}_{2}$ for 24 hours, supernatants were removed, centrifuged and investigated for IL-1 $\beta$, IL-6, IL-8, TNF $\alpha, 8$-isoprostane and $\mathrm{PGE}_{2}$ concentrations. The concentrations for IL- $1 \beta$ were; basal: $0 \mathrm{pg} / \mathrm{ml}, \mathrm{LPS}: 1670 \pm 570$ pg/ml, for TNFa; basal $24 \pm 42$ pg/ml, LPS: $7869 \pm 2087$ pg/ml, for IL-6 ; basal: 0 pg/ml, LPS: $20558 \pm 10815 \mathrm{pg} / \mathrm{ml}$, for IL-8; basal: $0 \mathrm{pg} / \mathrm{ml}$, LPS: $185 \pm 35 \mathrm{ng} / \mathrm{ml}$, for PGE2 basal: $287 \pm 27 \mathrm{pg} / \mathrm{ml}$, LPS: $19767 \pm 4455 \mathrm{pg} / \mathrm{ml}$, and for 8-isoprostane; basal $9 \pm 1 \mathrm{pg} / \mathrm{ml}$; LPS: 67 $\pm 1 \mathrm{pg} / \mathrm{ml}$. Original data was converted into \%-values of LPS-control and the means \pm SE were calculated.

Statistical Analysis. In every assay performed, the mean and the standard deviation were calculated and plotted to visualize differences between the average values of the experimental populations. Sample population means were compared against control population means in an unpaired two-tailed Student's $t$ test. The $\mathrm{p}$ value obtained from the Student's $\mathrm{t}$ test analysis marks the probability of rejecting the null hypothesis, that is, the events are independent, and they may be: $\mathrm{p} \leq 0.05$, significant $(*), \mathrm{p} \leq 0.01$, very significant $(* *)$ and $\mathrm{p} \leq 0.005$, highly significant $(* * *)$.

\section{RESULTS AND DISCUSSION:}

Processed coffee inhibits the release of proinflammatory mediators in human primary monocytes. It has been previously shown that coffee inhibits LPS-induced NF- $\kappa \mathrm{B}$ activation in the monocyte cell line U937 [13]. Since the NF- $\mathrm{BB}$ pathway is a master regulator of different proinflammatory mediators including cytokines [21], we evaluated the effect of processed coffee on LPS-stimulated human primary monocytes. The cells were incubated with increasing concentrations of the coffee for $30 \mathrm{~min}$ and then stimulated with LPS for 24 
hours. In figure $1 \mathrm{~A}$ we show that the coffee very effectively inhibited the release of all the cytokines tested. The IC50 for TNF $\alpha$, IL- 6 and IL-8 was calculated to be between 1 and 1.3 $\mu \mathrm{l} / \mathrm{ml}$ ( $\mathrm{vol} / \mathrm{vol}$ ), and the IC50 for IL-1 $\beta$ was significantly lower $(0.63 \mu \mathrm{l} / \mathrm{ml}$ ). At the concentration used we found that coffee was not cytotoxic for the cells (data not shown). The production of IL-1 $\beta$ in macrophages is regulated at the transcriptional and posttranscriptional levels, and therefore our results suggest that processed coffee may interfere with different targets involved in IL- $1 \beta$ release. We also found that coffee inhibited $\mathrm{PGE}_{2}$ release in LPS-stimulated monocytes (Fig. 1B). It has been shown that kahweol and cafestol inhibit COX-2 expression and $\mathrm{PGE}_{2}$ release in a murine macrophage cell line [22]. However, most of the phenolic compounds are retained in the filter during coffee preparation and it is possible that the effects of coffee on $\mathrm{PGE}_{2}$ release are mediated by compounds such as caffeine or by cyclopentanoids such as 3-methyl-1,2,-cyclopentadione (3-MCP). We have previously found that caffeine inhibits both COX-2 expression and enzymatic activity in primary microglia cells. Interestingly, caffeine synergizes with acetylsalicylic acid to inhibit $\mathrm{PGE}_{2}$ release [23]. Thus, it is possible that caffeine present in the processed coffee may synergize with compounds other than polyphenols to inhibit LPS-induced proinflammatory mediators and cytokines. In this sense it has been demonstrated that 3-MCP inhibits NF- $\kappa \mathrm{B}$ signaling, COX-2 and IL-6 expression in an in vivo model of inflammation [24]. It should be interesting to analyze the content of $3-\mathrm{MCP}$ in the processed coffee and its potential synergistic activities with caffeine.

Using the measurement of 8-isoprostane as a marker of free radical generation we show here that LPS induces a prooxidative state in primary monocytes leading to accumulation of 8-isoprostane. As depicted in Fig. 1B, processed coffee also inhibited the release of 8isoprostane in a concentration-dependent manner. The most important mechanisms associated with the toxic effects of enhanced COX activity during inflammation include production of $\mathrm{PGE}_{2}$ and formation of free radicals leading to oxidative stress [25,6]. Since the LPS-induced NF- $\kappa \mathrm{B}$ pathway is also mediated by an imbalance of the cellular redox status toward a prooxidative environment and NF- $\kappa \mathrm{B}$ is involved in the regulation of IL-1 $\beta$, TNF $\alpha$, IL-6, IL-8 and COX-2, it is possible that anti-oxidant compounds present in roasted coffee may account for the anti-inflammatory activities found in our experiments [13].

Drinking processed coffee prevents DSS-induced inflammation. One of the most used experimental models of colon inflammation is the dextran sulfate sodium (DSS) model of murine colitis. This is a well-established model of intestinal inflammation, which has some histological, and biochemical features of the human disease, especially with regard to the involvement of different inflammatory mediators, including eicosanoids and cytokines. As a result of the in vitro experiments, we were interested in testing the effects of processed coffee on murine IBD. Water was substituted by diluted $(50 \% / 50 \%$ coffee/water $\mathrm{vol} / \mathrm{vol})$ or undiluted coffee at least 2 weeks before DSS-treatment (Figure 2A). Both untreated (DSS group) and treated (Coffee groups) mice exhibited body weight loss beginning on day 4 of the DSS administration. By day 7, untreated mice exhibited a weight loss of nearly $20 \%$ of their initial body weights, whereas in animals drinking coffee the weight loss was less evident ( $<10 \%$ of initial body weight) (Fig. 2B). The score for stool consistence in untreated animals was 3.5, and this score was significantly reduced in animals that drank undiluted or diluted coffee (being 0.75 and 1.25 respectively). 
A)

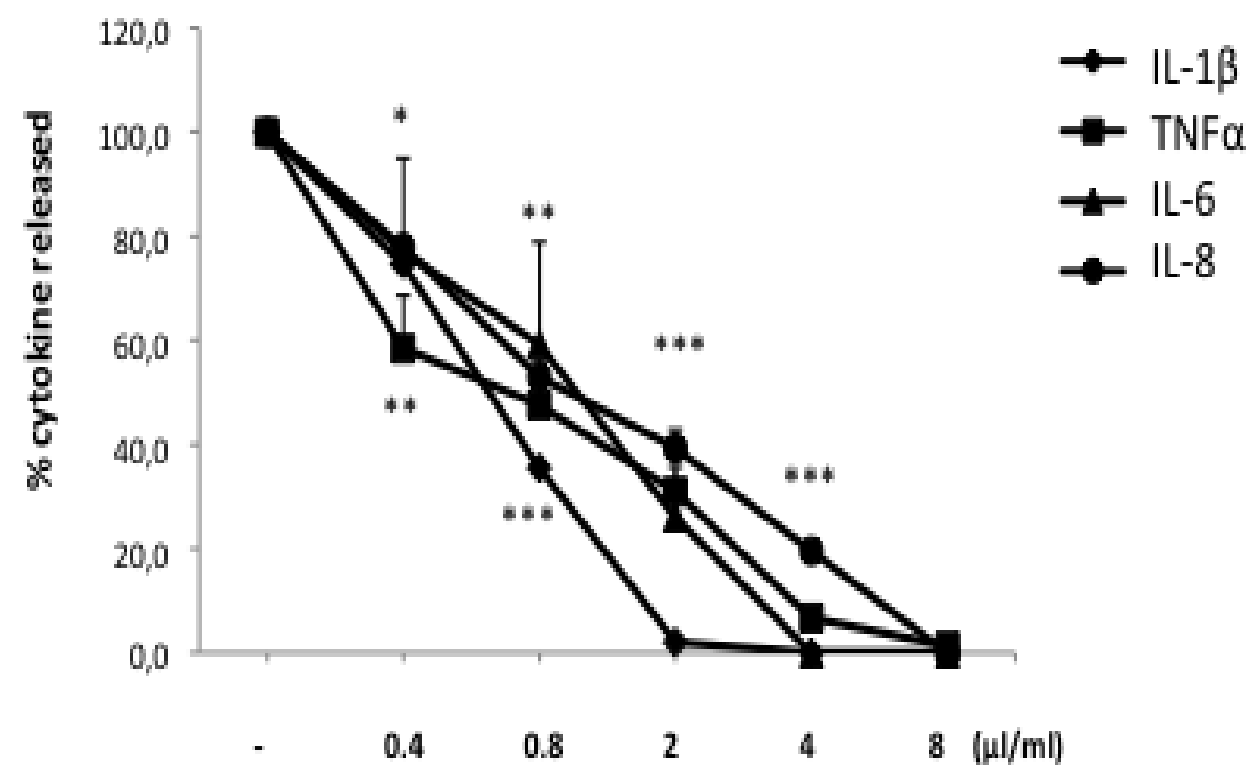

B)

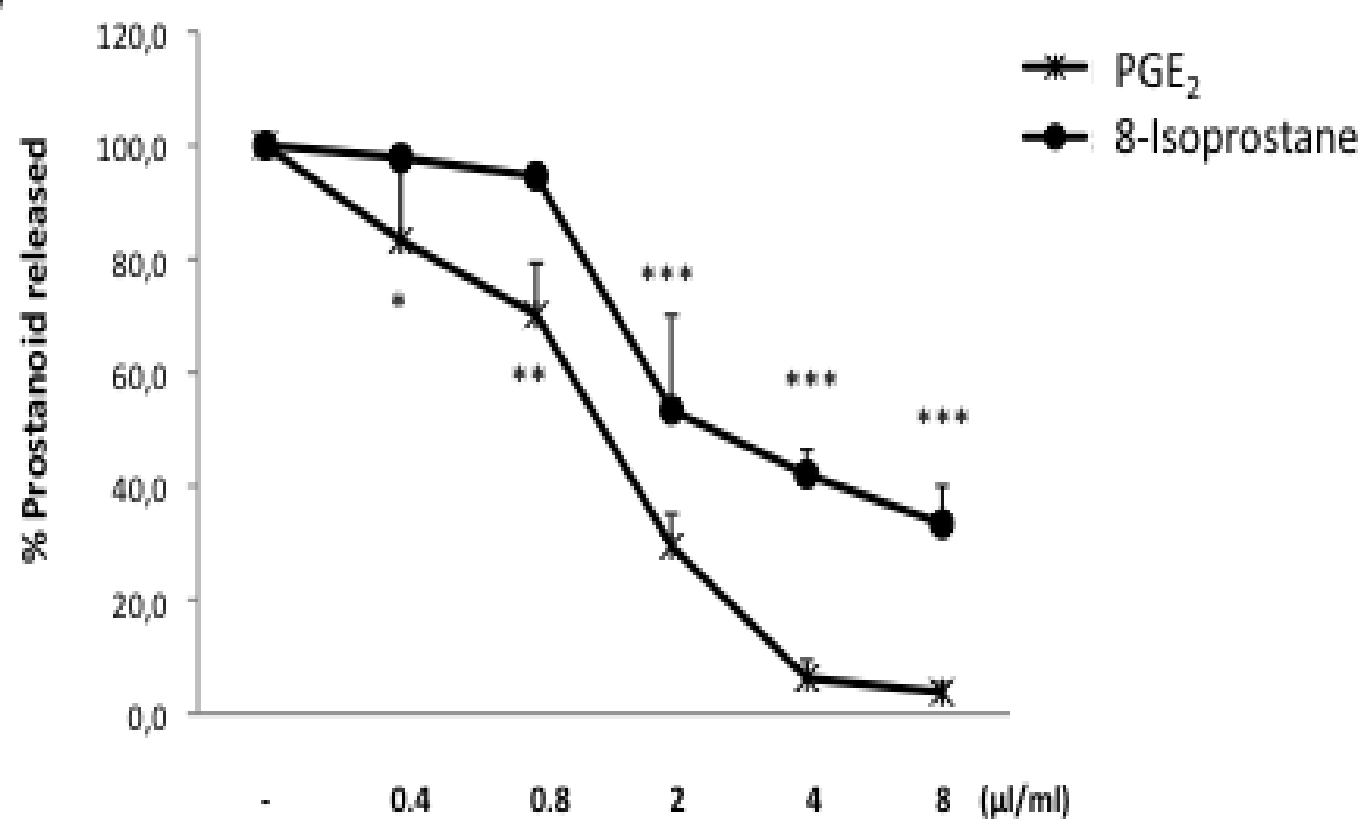

Figure 1. Processed coffee inhibits the release of proinflammatory mediators. Human primary monocytes were stimulated with LPS $(10 \mathrm{ng} / \mathrm{ml})$ as indicated and the release of proinflammatory cytokines (A) and eicosanoids (B) measured in the culture supernatants by either ELISA or EIA respectively. The graphs report the percentage of inhibition \pm S.D. values of three independent experiments. ${ }^{*} \mathrm{p}<0.05,{ }^{*} \mathrm{p}<0.01$ and ${ }^{* * *} \mathrm{p}<0.005$ in an unpaired two-tailed Student's $t$ test. 
A)

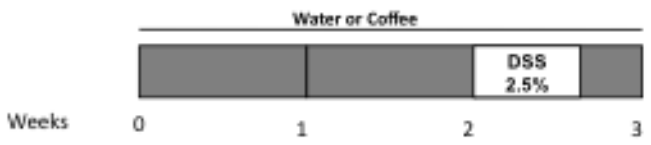

B)

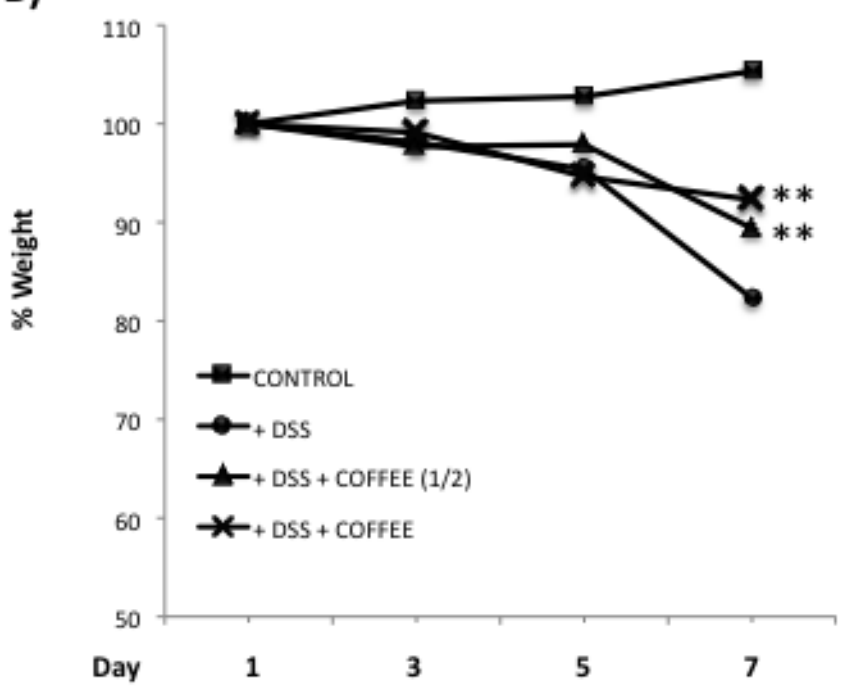

Figure 2. Coffee ameliorates weight loss in DSS-treated mice. (A) Schematic representation of the experimental procedure and DSS challenge. (B). The animals were weighed every other day during the last week of the experimental procedure. Six animals were included in every group and the weight at day 1 of DSS challenge was considered $100 \%$. The results are represented as the percentage of weight increase or weight loss. ${ }^{*} \mathrm{p}<0.01$ in an unpaired two-tailed Student's $t$ test.

A)

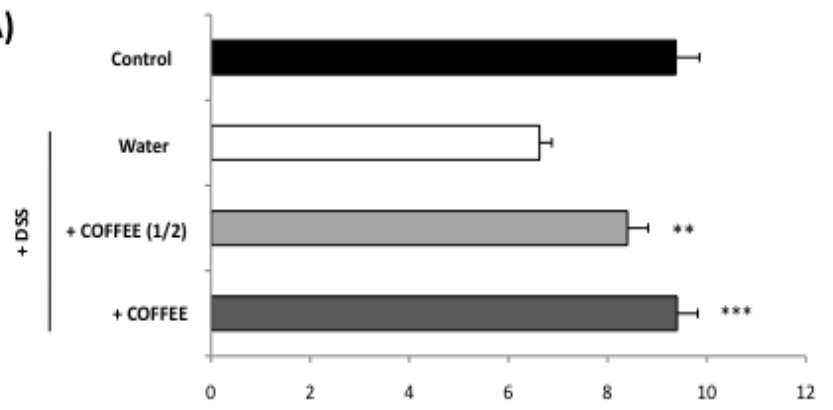

B)

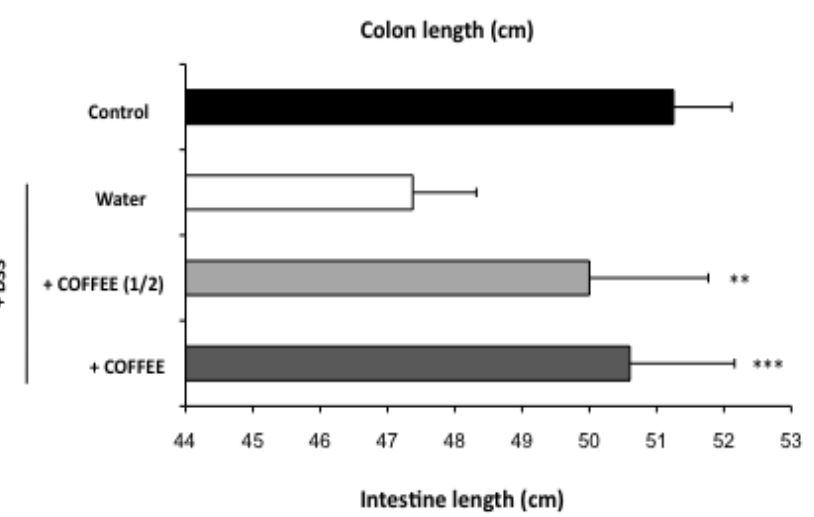

C)
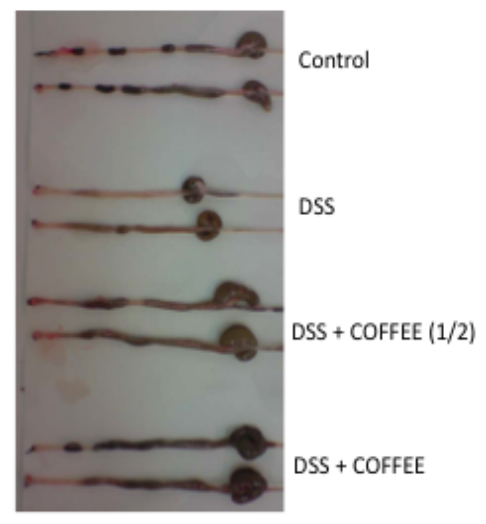

Figure 3. Coffee prevents colon retraction in DSS-treated mice. The different groups of animals (fig. 2) were sacrificed and both the colon length (A) and the total intestinal length 
(B) were measured. (C) Representative colons from each group of mice. The graphs report the mean \pm S.D. values of the measurements in six different animals. $* * p<0.01$ and $* * * p<$ 0.005 in an unpaired two-tailed Student's $t$ test.

Macroscopically, the colon length and total intestine length were markedly shorter in the untreated mice than in those drinking coffee (Fig. 3A, 3B). Histopathologically, untreated mice showed marked infiltration of inflammatory cells, loss of crypts, focal ulcerations and/or extensive destruction of the mucosal layer, accompanied by transmural infiltration of inflammatory cells, whereas coffee-treated mice showed mild infiltration of inflammatory cells in the mucosa and minimal loss of crypts in the group of animals that drank undiluted coffee (Fig. 4).

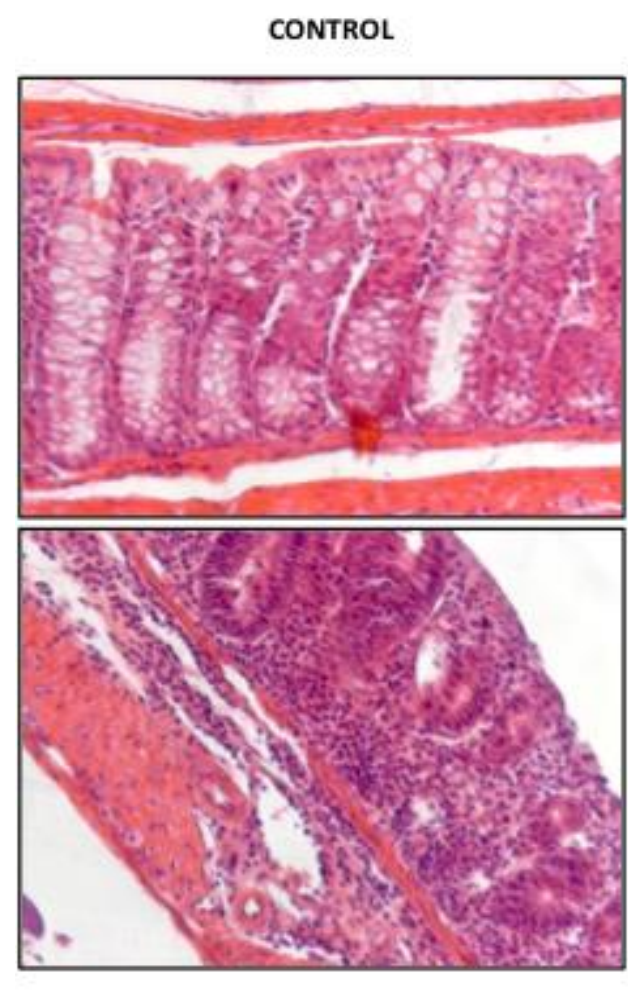

+ DSS + COFFEE $(1 / 2)$
+ DSS

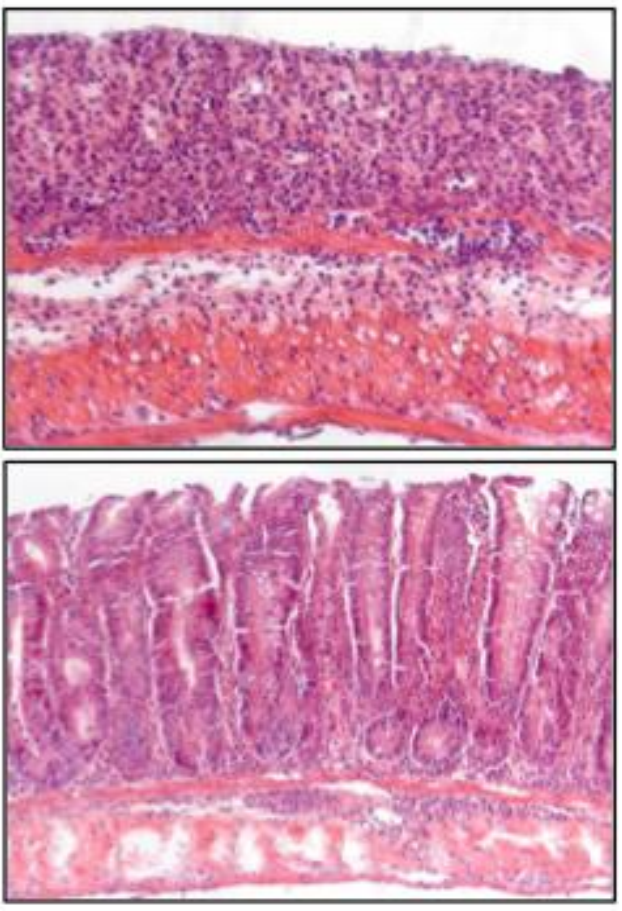

+ DSS + COFFEE

Figure 4. Coffee alleviates DSS-induced colon inflammation. The panels show sections of colon from control mice and from mice receiving $2.5 \%$ DSS in water, coffee solution (coffee) or coffee solution diluted 1:1 with water (coffee 1/2). The disruption of mucosal epithelium, the loss of glandular crypts and the infiltrate of inflammatory cells are clearly observed in DSS mice (DSS). In the colon section of DSS plus coffee-treated mice the glandular epithelium is almost intact and few inflammatory cells are present in the lamina propia.

Next, we explored the mRNA expression of proinflammatory markers in the colon of untreated (DSS group) and treated (Coffee groups) mice. We found that drinking coffee clearly prevented the expression of the proinflammatory genes COX-2, TNF $\alpha$, IL-6 and IL11, which were up regulated in the DSS group (Fig. 5A). Furthermore, we analyzed the NF$\kappa \mathrm{B}$ and STAT3 activation pathways by measuring the phosphorylation status of $\mathrm{I} \kappa \mathrm{B} \alpha$ and STAT3 proteins respectively. In figure 5B it is shown that treatment with DSS induced the phosphorylation of $\mathrm{I} \kappa \mathrm{B} \alpha$ and STAT3 in the colon, which was clearly inhibited in animals 
that drank coffee. Altogether, the results suggest that processed coffee significantly alleviates the inflammatory process in murine IBD.

A)

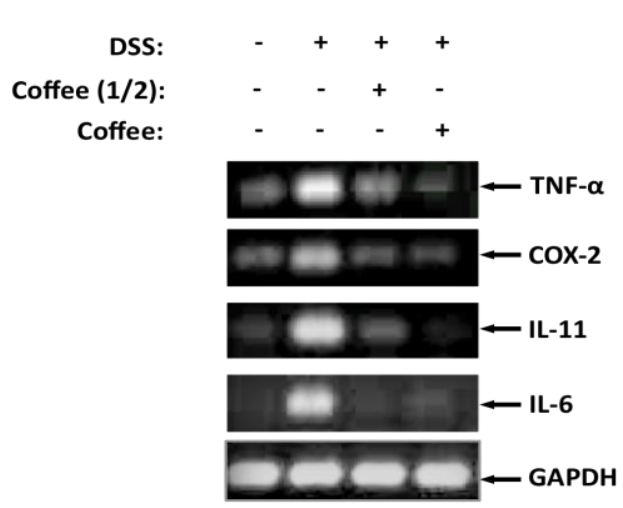

B)

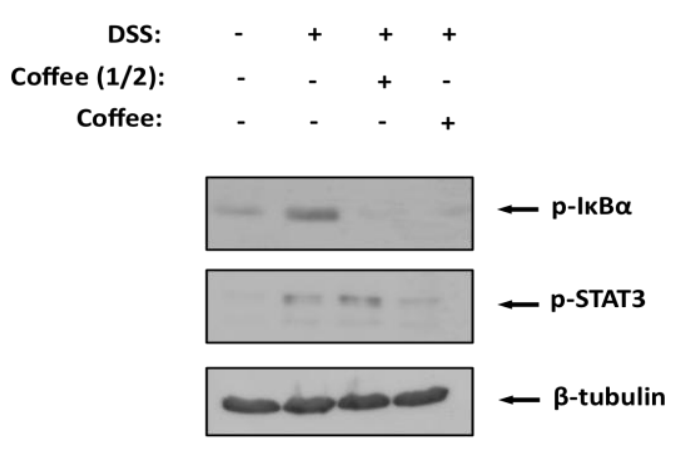

Figure 5. Processed coffee inhibits the expression of proinflammatory markers in the colon of DSS-treated animals. (A) TNF $\alpha$, COX-2, IL-6, IL-11 and GAPDH mRNA expression in the colon of control and treated animals. $(B)$ Western blot analysis of protein lysates from colons of control and treated animals. Phosphorylated forms of $\mathrm{I} \kappa \mathrm{B} \alpha$ and STAT3 are indicated by arrows. One of three independent experiments is shown.

The protective effects of coffee in the acute model of IBD may have also significance in the prevention of inflammation-associated diseases such as cancer and degenerative diseases. Proliferation and survival of tumor cells can be deeply affected by interactions with the surrounding microenvironment provided by chronic inflammation, which promotes different stages of carcinogenesis (tumor initiation, progression, angiogenesis and metastasis). During the initial stages, immune and stromal cells provide inflammatory signals that favor malignant-cell growth [27].

Many epidemiological and experimental studies have highlighted the relevance of inflammation as a predisposing cause of cancer [16,17], and coffee consumption may protect from colon carcinogenesis [7]. We have found that coffee prevents NF- $\kappa$ B and STAT3 activation, and these transcription factors are known to regulate in a cooperative manner several proinflammatory genes, such as IL-6, IL-11, chemokines, growth factors and COX-2, which are crucial for maintaining a pro-carcinogenic inflammatory environment [19][28]. Therefore, STAT3 and NF- $\kappa$ B establish a feed-forward loop between cancer cells and the tumor microenvironment, thus creating a crosstalk between tumor cells and the surrounding inflammatory environment. This complex interplay between NF- $\kappa \mathrm{B}$ and STAT3 signaling cascades in different cell types (epithelial and inflammatory myeloid cells) has recently been deciphered in different studies using murine models of colitis-associated cancer [29]. Therefore, it was proposed that IL-6 released by myeloid cells would activate STAT3 in adjacent premalignant endothelial cells, thereby stimulating proliferation and tumor growth [30].

\section{CONCLUSIONS:}

Our results demonstrate that processed coffee dampens a crucial mechanism in colon inflammation. Coffee contains a vast number of bioactive compounds that are retained after 
bean processing and roasting. Therefore, a "stomach friendly coffee" may not only prevent gastric irritation but its consumption may be also of nutritional importance for the management of chronic inflammatory diseases.

List of Abbreviations Used: LPS: Lipopolysaccharide; IL: interleukin; TNF: tumor necrosis factor; PG: prostaglandin; DSS: dextran sodium sulfate; NF-кB: nuclear factor kappa B; STAT3: signal transducer and activator of transcription 3; COX: cyclooxygenase

Competing Interests: There are no conflicts of interest.

Author's Contribution: B.L.F. and E.M conceived and design the experiments. T.R. performed the in vitro experiments with monocytes. A.G.V., G.S.D. and J.A.C. performed the in vivo experiments. B.L.F., AG.V., G.S.D. and E. M. analyzed all the data. B.F.L., J.M., and E.M. contributed to the writing of the paper and approved the final version of the manuscript.

\section{REFERENCES:}

1. Andersen LF, Jacobs Jr. DR, Carlsen MH, and Blomhoff R: Consumption of coffee is associated with reduced risk of death attributed to inflammatory and cardiovascular diseases in the Iowa Women's Health Study. Am J Clin Nutr 2006; 83:1039-1046.

2. Palacios N, Gao X, McCullough ML, Schwarzschild MA, Shah R, Gapstur S, Ascherio A: Caffeine and risk of Parkinson's disease in a large cohort of men and women. Mov Disord. 2012; 27:1276-82

3. Ruhl CE, Everhart JE: Coffee and tea consumption are associated with a lower incidence of chronic liver disease in the United States. Gastroenterology 2005; 129: 1928-1936.

4. Sang LX, Chang B, Li XH, Jiang M: Consumption of coffee associated with reduced risk of liver cancer: a meta-analysis. BMC Gastroenterol 2013: 25:13-34.

5. von Ruesten A, Feller S, Bergmann MM, Boeing H: Diet and risk of chronic diseases results from the first 8 years of follow-up in the EPIC-Potsdam study. Eur J Clin Nutr. 2013; 67:412-9.

6. Doo T, Morimoto Y, Steinbrecher A, Kolonel LN, Maskarinec G: Coffee intake and risk of type 2 diabetes: the Multiethnic Cohort. Public Health Nutr 2013; 27:1-9.

7. Giovannucci E: Meta-analysis of coffee consumption and risk of colorectal cancer. Am J Epidemiol 1998; 147: 1043-1052.

8. Ullman TA, Itzkowitz SH: Intestinal inflammation and cancer. Gastroenterology 2011; 140: 1807-1816.

9. Nunes FM, Coimbra MA: Melanoidins from coffee infusions. Fractionation, chemical characterization, and effect of the degree of roast. J Agric Food Chem 2007; 55: 3967-3977

10. Darboven A: Method for the quality improvement of raw coffee by treatment with steam and water. EP 0755631 (B1). April 3, 1997.

11. Ehrlich A, Basse H, Henkel-Ernst J, Hey B, Menthe J, Lücker PW: Effect of differently processed coffee on the gastric activity difference and intragastric $\mathrm{pH}$ in healthy volunteers. Methods Find Exp Clin Pharmacol 1998; 20: 155- 161. 
12. Ehrlich A, Lücker PW, Schaefer A: Effect of processed and non-processed coffee samples on gastric potential difference. Study with healthy male Helicobacter pyloripositive and Helicobacter pylori-negative volunteers. Arzneimittelforschung 1999; 49:626-630.

13. Paur I, Balstad TR, Blomhoff R: Degree of roasting is the main determinant of the effects of coffee on NF-kappaB and EpRE. Free Radic Biol Med 2010; 48:1218-27.

14. Lam LK, Sparnins VL, Wattenberg LW: Effects of derivatives of kahweol and cafestol on the activity of glutathione S-transferase in mice. J Med Chem 1987; 30:1399-1403.

15. Lutgens MW, van Oijen MG, van der Heijden GJ, Vleggaar FP, Siersema PD, Oldenburg B: Declining risk of colorectal cancer in inflammatory bowel disease: an updated meta-analysis of population-based cohort studies. Inflamm Bowel Dis 2013; 19:789-99

16. Mantovani A, Allavena P, Sica A, Balkwill, F: Cancer-related inflammation. Nature 2008; 454:436-444.

17. Karin M, Greten, FR: NF-kappaB: linking inflammation and immunity to cancer development and progression. Nat Rev Immunol 2005; 5:749-759.

18. Yu H, Pardoll D, Jove R: STATs in cancer inflammation and immunity: a leading role for STAT3. Nat Rev Cancer 2009; 9:798-809.

19. Grivennikov SI, Karin M: Dangerous liaisons: STAT3 and NF-kappaB collaboration and crosstalk in cancer. Cytokine Growth Factor Rev 2010; 21:11-19.

20. Cooper HS, Murthy SN, Shah RS, Sedergran DJ: Clinicopathologic study of dextran sulfate sodium experimental murine colitis. Lab Investig 1993; 69:238-249.

21. Hayden MS, Ghosh S: NF-кB in immunobiology. Cell Res 2011; 21:223-44.

22. Kim JY, Jung KS, Jeong HG: Suppressive effects of the kahweol and cafestol on cyclooxygenase-2 expression in macrophages. FEBS Lett 2004; 569:321-6.

23. Fiebich BL, Lieb K, Hüll M, Aicher B, van Ryn J, Pairet M, Engelhardt G: Effects of caffeine and paracetamol alone or in combination with acetylsalicylic acid on prostaglandin E(2) synthesis in rat microglial cells. Neuropharmacology 2000; 39: 2205-13.

24. Chung JH, Choi SY, Kim JY, Kim DH, Lee JW, Choi JS, Chung HY: 3-methyl-1,2cyclopentanedione down-regulates age-related NF-kappaB signaling cascade. J Agric Food Chem 2007; 55:6787-92.

25. Candelario-Jalil E, Akundi RS, Bhatia HS, Lieb K, Appel K, Muñoz E, Hüll M, Fiebich BL: Ascorbic acid enhances the inhibitory effect of aspirin on neuronal cyclooxygenase-2-mediated prostaglandin E2 production. J Neuroimmunol 2006; 174:39-51.

26. Akundi RS, Candelario-Jalil E, Hess S, Hüll M, Lieb K, Gebicke-Haerter PJ, Fiebich BL: Signal transduction pathways regulating cyclooxygenase- 2 in lipopolysaccharideactivated primary rat microglia. Glia 2005;51:199-208.

27. Grivennikov SI, Greten FR, Karin M: Immunity, inflammation, and cancer. Cell 2010; 140:883-899.

28. Bollrath J, Greten FR: IKK/NF-kappaB and STAT3 pathways: central signalling hubs in inflammation-mediated tumour promotion and metastasis. EMBO Rep 2009; 10:1314-1319. 
29. Greten FR, Eckmann L, Greten TF, Park JM, Li ZW, Egan LJ, Kagnoff MF, Karin M: IKKbeta links inflammation and tumorigenesis in a mouse model of colitis-associated cancer. Cell 2004; 118:285-296.

30. Becker C, Fantini MC, Schramm C, Lehr HA, Wirtz S, Nikolaev A, Burg J, Strand S, Kiesslich R, Huber S, Ito H, Nishimoto N, Yoshizaki K, Kishimoto T, Galle PR, Blessing M, Rose-John S, Neurath MF. TGF-beta suppresses tumor progression in colon cancer by inhibition of IL-6 trans-signaling. Immunity 2004; 21:491-501. 